\title{
Mathematical Model of Homogeneous Corrosion of Steel Pipe Pile Foundation for Offshore Wind Turbines and Corrosive Action
}

\author{
Kui Wang and Ming-jie Zhao \\ Key Laboratory of Hydraulic and Waterway Engineering of the Ministry of Education, Chongqing Jiaotong University, \\ Chongqing 400074, China \\ Correspondence should be addressed to Kui Wang; anhuiwk@163.com
}

Received 18 December 2015; Accepted 16 June 2016

Academic Editor: Seung-Jun Kwon

Copyright ( 92016 K. Wang and M.-j. Zhao. This is an open access article distributed under the Creative Commons Attribution License, which permits unrestricted use, distribution, and reproduction in any medium, provided the original work is properly cited.

\begin{abstract}
In this paper, the nonlinear corrosion model under the combined action of the anticorrosion system and corrosive environment is chosen as the mathematical model of homogeneous corrosion of steel pipe pile foundation for the offshore wind turbine. Based on the mathematical model, a three-dimensional finite element model was established for the steel pipe pile foundation of the offshore wind turbine. And the homogeneous corrosion action of the steel pipe piles was calculated, and the reduction rules of the strength and stability of the steel pipe piles for wind turbines under different corrosion patterns are analyzed. According to the calculation results, the mathematical model can be used in the analysis of corrosion for steel pipe pile in the wind turbine. Under the normal operation conditions, the reduction rules of the strength and stability of the steel pipe piles contain three stages: no influence stage, negative exponential decrease stage, and stable stage. But under the extreme load conditions, the effect of corrosion is enormous for the strength and stability of the steel pipe pile.
\end{abstract}

\section{Introduction}

Offshore wind power resources serve as renewable green energy resources. Rapid development of the offshore wind power industry is the main direction for development of clean energy. However, offshore wind power plants are in the marine environment and the hydrological, meteorological, and submarine geological conditions are complex making it difficult to construct offshore wind power plants. Particularly, the wind turbine foundation as the major structure is in the marine corrosive environment for a long period of time. Thus, anticorrosion of the wind turbine foundation is one of the problems to be first solved in construction of wind turbines.

European countries started research on offshore wind power generation in as early as 1970s. To solve the highly corrosive effect of the marine environment on the wind turbine foundation, many scholars have been studying the corrosion resistance of the offshore steel structure. For example, Jeffrey and Melchers [1] studied the corrosion rate of metal in the marine environment; Kim et al. [2] studied the effect of alloy elements on the corrosion resistance of steel. Wang et al. [3] studied the corrosion rate of the alloy steel by conducting corrosion tests for different types of alloy steel. Ma and Wen [4] and TSCF [5] studied the principle for alloy steel corrosion. Melchers [6] obtained an equivalent thickness computational formula involving multiple parameters such as boundary conditions, steel plate dimensions, bending rigidity, and quality based on the bending test and theoretical derivation after pitting corrosion occurred to the steel plate. Melchers et al. [7, 8] created extreme value distribution (generally Gumbel distribution) for the maximum pit depth of the steel structure corrosion based on the pitting corrosion test in the seawater continuous immersion zone. Based on the "phenomenological model," they proposed the probabilistic model of maximum pit depth. The offshore wind power industry in China is also rising rapidly under the substantial policy support given to clean energy particularly the development of wind power. The researchers have conducted substantial research on anticorrosion in the marine environment. For example, Hou [9] has conducted a great 
deal of experimental research on the characteristics of metal corrosion and systematically studied the marine corrosion theory. Jiang et al. [10] have focused on the anticorrosion of the coating for the offshore wind turbine foundation and studied the coating used for anticorrosion of the steel pipe pile foundation for wind driven generators. Zhang and Li [11] have proposed a new composite sacrificial anode anticorrosive system with better preservative effect. Liu et al. [12] have conducted grouping experiments for the sacrificial anode of the composite aluminum alloys of different coating thickness.

At present, there is some research on corrosion of various traditional maritime steel structures but there is little research on corrosion and protection of the offshore wind turbine foundation. And there is nearly no research on the rules of effect of corrosion on the wind turbine foundation.

\section{Research on the Mathematical Model of Homogeneous Corrosion of the Offshore Steel Pipe Pile Foundation}

2.1. Analysis of the Mechanism of Homogeneous Corrosion of the Offshore Steel Pipe Pile Foundation. The types of corrosion of the steel pipe piles for the wind turbine in the marine environment can be divided into homogeneous corrosion and local corrosion. Homogeneous corrosion is one of the major causes of damage to offshore steel pipe pile for the wind turbine. Local corrosion includes pitting corrosion, crevice corrosion, impingement corrosion, cavitation corrosion, and galvanic corrosion. Occurrence of such corrosion behaviors is often associated with structural design or steel smelting.

Homogeneous corrosion refers to the corrosion occurring at almost the same rate on the surface of the steel pipe pile for the wind turbine, which is one of the major causes of structural corrosion damage. It is different from the general corrosion of arbitrary pattern produced on the surface of the steel pipe pile structure and that on the metal surface. Homogeneous corrosion generally occurs in an area where the anode region and the cathode region are difficult to be distinguished at macro level. In other words, this is a corrosion pattern with service life easily predictable.

2.2. Mathematical Model of Homogeneous Corrosion of the Offshore Steel Pipe Pile Foundation. At present, there is focus on homogeneous corrosion in terms of the effect of corrosion on the structural strength. In most of the traditional research on corrosion, the corrosion rate is simplified as a random variable with a constant mean value; that is, it is assumed that the thickness of the steel structure is decreasing linearly with time. As a permanent construction, the offshore wind turbine foundation must be designed in such a manner that anticorrosion is considered before it is put into use. Therefore, when it comes to the corrosion characteristics of the offshore steel pipe pile structure for the wind turbine, the effective function of the corrosion protection system (CPS) must be taken into consideration.

Qin et al. [13] (2003) considered the interaction between CPS and environment and proposed a new mathematical model of nonlinear corrosion based on the Guedes Soares model. They pointed out that the corrosion rate of the structural CPS was in rough conformity with Weibull distribution; nevertheless the corrosion rate tended to be normally distributed in a severe corrosive environment. The corrosion rate is expressed as

$$
\begin{aligned}
& V(t) \\
& = \begin{cases}0, & 0 \leq t<T_{\text {st }}, \\
d_{\infty} \frac{\beta}{\eta}\left(\frac{t-T_{\text {st }}}{\eta}\right)^{\beta-1} \exp \left[-\left(\frac{t-T_{\text {st }}}{\eta}\right)^{\beta}\right], & T_{\text {st }} \leq t \leq T_{L},\end{cases}
\end{aligned}
$$

where $\beta$ and $\eta$ are undetermined coefficients, $d_{\infty}$ is the limit corrosion thickness, $T_{\text {st }}$ is the moment when the structural corrosion of steel starts and it can be obtained by measurement, and $T_{L}$ is the service life of the structure.

Based on the integral of time $t$ in expression (1), the corrosion thickness at any time is

$$
\begin{aligned}
& d(t) \\
& = \begin{cases}0, & 0 \leq t<T_{\text {st }}, \\
d_{\infty}\left\{1-\exp \left[-\left(\frac{t-T_{\text {st }}}{\eta}\right)^{\beta}\right]\right\}, & T_{\text {st }} \leq t \leq T_{L} .\end{cases}
\end{aligned}
$$

In fact, the corrosion protection system for the offshore steel pipe pile structure for the wind turbine is a gradual failure process, and the corrosion of the steel pipe piles has started before complete failure. $T_{\text {st }}$ and $T_{L}$ can be used to describe the protection performance of the corrosion protection system for the offshore steel pipe piles for the wind turbine. Therefore, it is feasible to describe the complex corrosion behavior of the offshore steel pipe pile for the wind turbine using the mathematical model of Weibull distribution.

Based on the data of partial corrosion of the low alloy steel in the marine environment at Qingdao Corrosion Test Station, it is assumed that the corrosion data of the low alloy steel in the marine environment is as shown in Table 1.

It is assumed that the corrosion data in Table 1 are in conformity with the mathematical model of Weibull distribution. Then, we can obtain $T_{\text {st }}=3.8 \mathrm{a}, \beta=1.99$, $\eta=9.19$, and $d_{\infty}=7.5 \mathrm{~mm}$. The corrosion thickness and the corrosion rate of the offshore steel pipe pile for the wind turbine are as shown in the following formulas:

$$
d(t)= \begin{cases}0, & 0 \leq t<3.8, \\ 7.5\left\{1-\exp \left[-\left(\frac{t-3.8}{9.19}\right)^{1.99}\right]\right\}, & 3.8 \leq t \leq T_{L},\end{cases}
$$

$$
= \begin{cases}0, & 0 \leq t<3.8, \\ 7.5 \frac{1.99}{9.19}\left(\frac{t-3.8}{9.19}\right)^{0.99} \exp \left[-\left(\frac{t-3.8}{9.19}\right)^{1.99}\right], & 3.8 \leq t \leq T_{L} .\end{cases}
$$

If it is defined that the parameter $\Gamma$ indicates the corrosion rate of the steel pipe pile foundation, the relationship between the corrosion rate and time of the steel pipe pile foundation is as shown in Figure 1. 
TABle 1: Corrosion data.

\begin{tabular}{lcc}
\hline Time (annual) & Mean value $(\mathrm{mm})$ & Standard deviation \\
\hline 2 & 0.02 & 0.01 \\
3 & 0.05 & 0.01 \\
3.5 & 0.09 & 0.01 \\
4 & 0.28 & 0.15 \\
4.5 & 0.34 & 0.15 \\
5 & 0.68 & 0.15 \\
6 & 1.02 & 0.20 \\
7 & 1.43 & 0.20 \\
8 & 2.08 & 0.20 \\
9 & 2.82 & 0.5 \\
10 & 2.63 & 0.5 \\
11 & 4.82 & 0.5 \\
12 & 5.50 & 0.5 \\
13 & 5.96 & 0.5 \\
14 & 6.48 & 0.80 \\
15 & 7.08 & 0.80 \\
16 & 7.24 & 0.80 \\
17 & 7.36 & 0.80 \\
18 & 7.43 & 0.80 \\
19 & 7.47 & 0.80 \\
20 & 7.50 & 0.80 \\
\hline & &
\end{tabular}

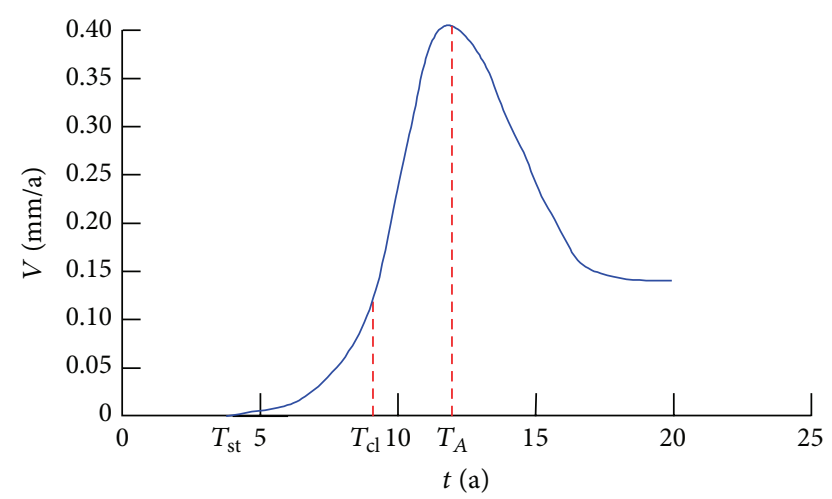

FIGURE 1: Corrosion rate curve for offshore steel pipe piles for wind turbines.

Based on the model, the development regularity of the homogeneous corrosion rate of the offshore steel pipe pile for the wind turbine can be divided into four stages.

(1) $t \in\left[0, T_{\text {st }}\right]$ : the corrosion protection system for the offshore steel pipe pile for the wind turbine is operating properly; no corrosion occurs.

(2) $t \in\left[T_{\mathrm{st}}, T_{\mathrm{cl}}\right]$ : the corrosion protection system and the corrosive environment are interacting; the corrosion system is experiencing gradual failure; the corrosion rate of the steel pipe pile starts to increase slowly.

(3) $t \in\left[T_{\mathrm{cl}}, T_{A}\right]$ : the corrosion protection system completely fails; the corrosion rate of the steel pipe pile increases exponentially; the corrosion rate can reach a peak value.
(4) $t \in\left[T_{A}, T_{L}\right]:$ the corrosion rate of the steel pipe pile decreases rapidly and enters the stable development state due to the protective effect of the passive film.

\section{Analysis of Mathematical Model of Homogeneous Corrosion of Steel Pipe Pile Foundation for Offshore Wind Turbines and Corrosive Action}

A three-dimensional finite element model is established for the steel pipe pile foundation of the offshore wind turbine under the condition of homogeneous corrosion. A numerical simulation calculation is performed for the homogeneous corrosion of the steel pipe piles for wind turbines. Then, the strength and stability of the steel pipe piles for wind turbines under the condition of homogeneous corrosion are calculated on the basis of the mathematical model of homogeneous corrosion of offshore steel pipe pile for the wind turbine.

3.1. Model Design. The single steel pipe pile foundation for the wind turbine in Donghai Bridge offshore wind power plant is taken as an example. The large scale general finite element analysis software ANSYS 10.0 is used to establish a three-dimensional finite element model for the wind turbine foundation and groundwork. As shown in Figure 1, the total length of a single steel pipe pile is $65 \mathrm{~m}$, the diameter of pile is $4.0 \mathrm{~m}$, the wall thickness of steel pipe pile is $50 \mathrm{~mm}$, seabed insertion depth is $40 \mathrm{~m}$, and the average seawater depth is $15 \mathrm{~m}$.

59 pipe units are used as the steel pipe piles above the sea mud level. 16 pipe units are used as the steel pipe piles below the sea mud level. For the foundation soil body, the COMBIN39 nonlinear spring element is used to express the $P-y$ curve for interaction between the steel pipe pile and the soil around pile. Based on the checking calculation result of the axial bearing capacity of the pile foundation, the axial bearing capacity is much greater than the vertical load. Thus, it is considered that no displacement occurs in the axial direction. Boundary conditions are as follows: axial fixed constraint for the pile foundation bottom and radial spring constraint for the outside. Based on the dimension ratio of the steel pipe piles, the calculation models and grids are as shown in Figure 2.

\subsection{Calculation Parameters}

(1) Environmental Parameters. Average seawater depth is $18 \mathrm{~m}$, seawater density is $1030 \mathrm{~kg} / \mathrm{m}^{3}$, wind speed is $38 \mathrm{~m} / \mathrm{s}$ at $8 \mathrm{~m}$ above the seal level, significant wave height is $5.8 \mathrm{~m}$, significant wave period is $7.4 \mathrm{~s}$, flow rate on the sea surface is $1.73 \mathrm{~m} / \mathrm{s}$, middle flow rate is $1.37 \mathrm{~m} / \mathrm{s}$, bottom flow rate is $0.95 \mathrm{~m} / \mathrm{s}$, and soft clay is at $10 \mathrm{~m}$ below the mud surface.

(2) Material Parameters. The steel pipe piles use low alloy high-strength steel Q345E with yield strength of $345 \mathrm{MPa}$, much lower than soil strength. Thus, the linear material model can be used. Elasticity modulus is $2.1 \times 10^{5} \mathrm{MPa}$, 


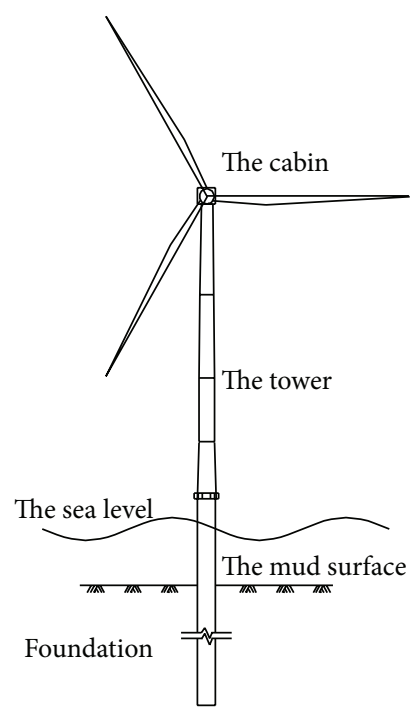

(a) Single pile foundation for offshore wind turbines

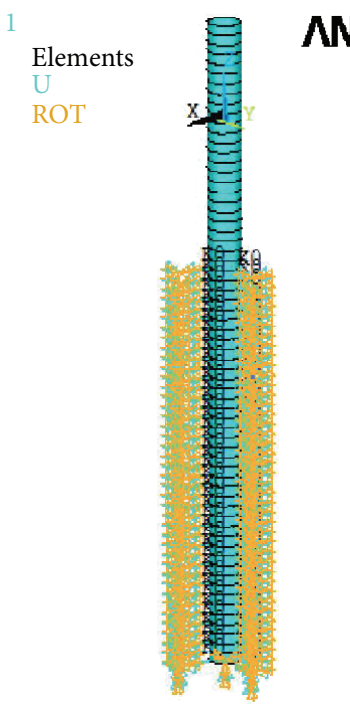

(b) The grids of single steel pipe pile foundation for wind turbines

FIGURE 2: Finite element model of single steel pipe pile foundation for wind turbines.

Poisson's ratio is 0.3 , and low alloy steel density is $7.85 \times$ $10^{3} \mathrm{~kg} / \mathrm{m}^{3}$.

3.3. Working Condition of Calculation. In accordance with Design Specification for Groundsill Foundation for Wind Turbine Generators (FD 003-2007) and Shanghai Authentication Specification for Wind Turbine Generators (China Classification Society, 2012), accidental seismic load conditions, extreme load conditions, and normal load conditions should be considered in calculation of the groundwork design load for the offshore wind power. In consideration of the minor combined effect of the accidental seismic load and corrosion of the wind turbine foundation, the paper is intended to study the effect of corrosion on strength and stability of the pile foundation structure under the conditions of extreme loads and normal operation. The extreme load condition is the combined effect of the extreme loads transferred from the upper structure plus other extreme loads applied on the foundation structure. The normal operation load condition is the combined effect of normal operation loads transferred from the upper structure plus other normal operation loads applied on the foundation structure. The load conditions are as shown in Table 2.

3.4. Calculation Results. As the maintenance period of the corrosion protection system for the offshore wind turbine foundation generally does not exceed 20 years, analog computations are performed for corrosion in 20 years of operation of the steel pipe pile for the wind turbine to obtain the deflection and equivalent stress of the pile foundation at different point in time. The deflection and equivalent stress of the pile foundation under the normal operation condition when $t=10$ a are shown in Figure 3.
TABLE 2: Load conditions.

\begin{tabular}{lccc}
\hline Load on pile top & $\begin{array}{c}\text { The } \\
\text { horizontal } \\
\text { force/KN }\end{array}$ & $\begin{array}{c}\text { The vertical } \\
\text { force/KN }\end{array}$ & $\begin{array}{c}\text { Bending } \\
\text { moment/KN.m }\end{array}$ \\
\hline $\begin{array}{l}\text { Normal operation } \\
\text { condition }\end{array}$ & 208 & 4700 & 13324 \\
$\begin{array}{l}\text { Extreme load } \\
\text { condition }\end{array}$ & 2005 & 4700 & 112332 \\
\hline
\end{tabular}

(1) It is known from the calculation result of the normal operation condition that the corrosion rate of the wind turbine foundation increases continuously with the time of exposure to the corrosive medium. The maximum deflection of the pile top increases from $7.02 \mathrm{~cm}$ to $11.0 \mathrm{~cm}$, and the maximum stress increases from $50.6 \mathrm{Mpa}$ to $98.5 \mathrm{Mpa}$. The development of the maximum deflection and maximum stress under the normal condition and influence of corrosion is as shown in Figures 4 and 5.

(2) The calculation result of the wind turbine foundation under an extreme load condition: under the condition of noncorrosion $(t \leq 2.3 \mathrm{a})$, maximum deflection $y=12.5 \mathrm{~cm}$ and maximum stress $\sigma_{\max }=92.8 \mathrm{Mpa}$. When $t=20 \mathrm{a}$, maximum deflection of pile foundation $y=41.3 \mathrm{~cm}$ and maximum stress $\sigma_{\max }=289 \mathrm{Mpa}$. The curve for maximum deflection and maximum stress of the pile foundation increasing with corrosion time is shown in Figures 6 and 7, respectively.

\section{Analysis and Discussion}

\subsection{Normal Operation Conditions}

(1) Analysis of Pile Foundation Strength. In accordance with Authentication Specification for Wind Turbine Generators (China Classification Society, 2002), to ensure safe use of the 


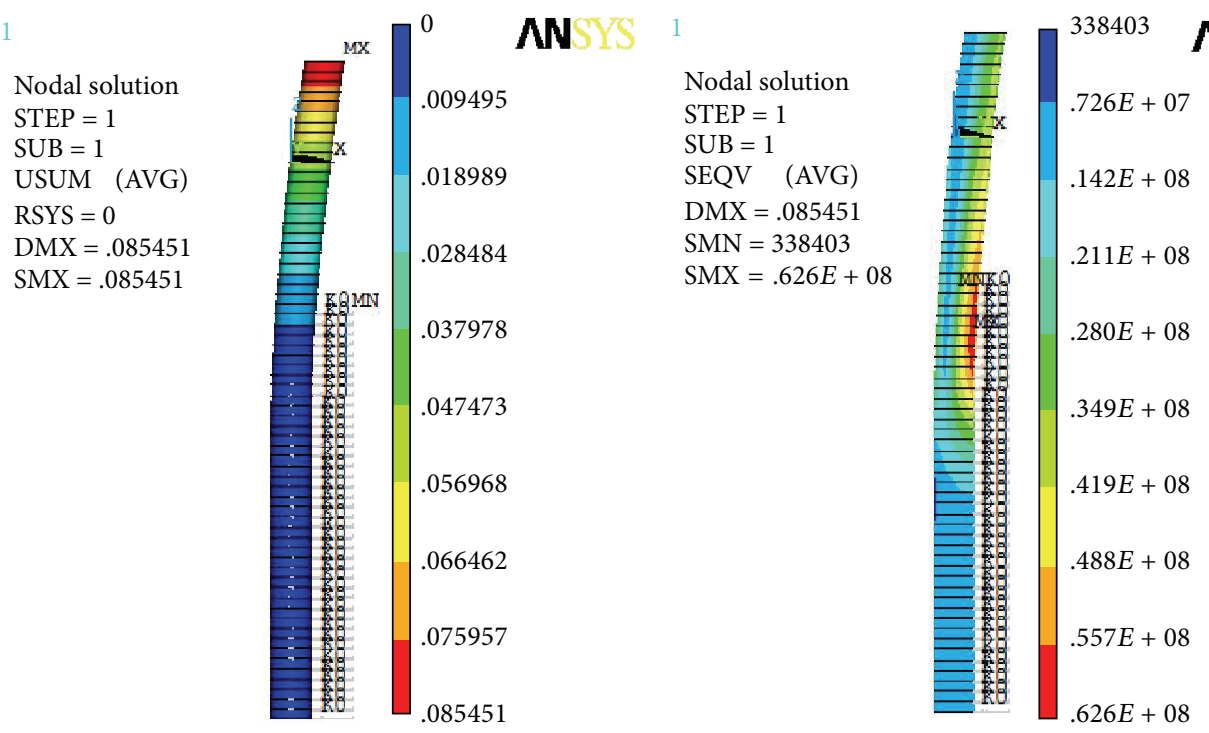

(a) The deflection

(b) The equivalent stress

FIGURE 3: Deformation and stress of pile foundation under normal operation condition when $t=10 \mathrm{a}$.

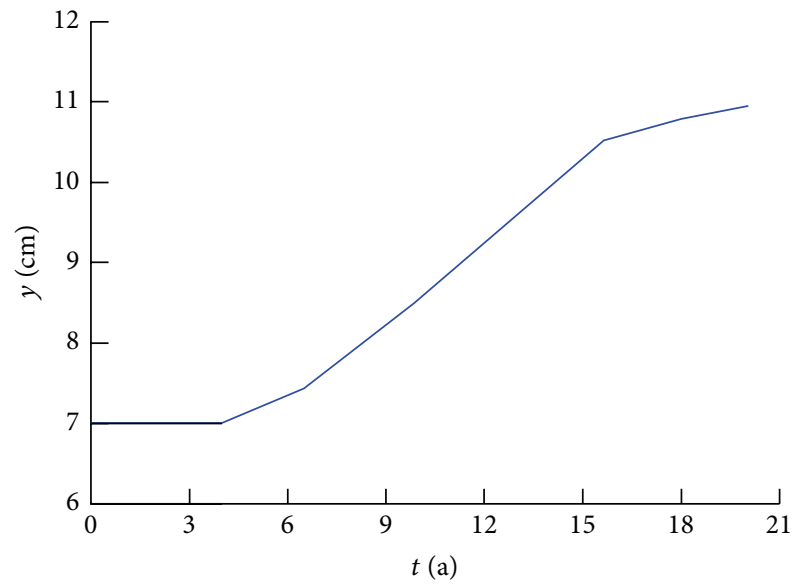

Figure 4: Curve of development of maximum deflection of pile foundation under normal operation condition.

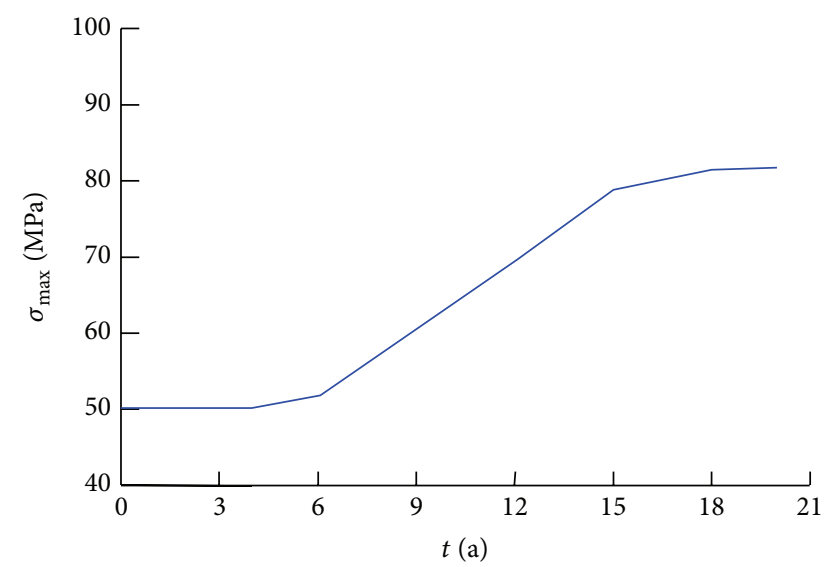

FIGURE 5: Curve of development of maximum stress of pile foundation under normal operation condition.

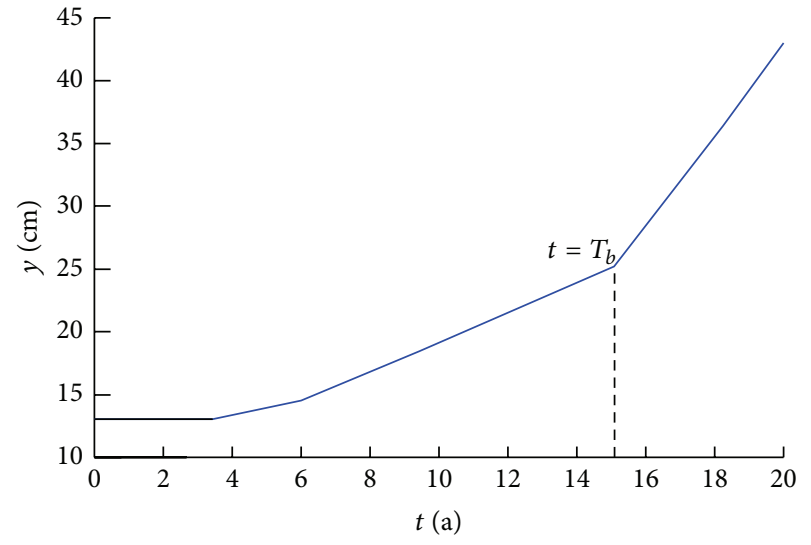

FIGURE 6: Curve of development of maximum deflection of pile foundation under the condition of extreme load.

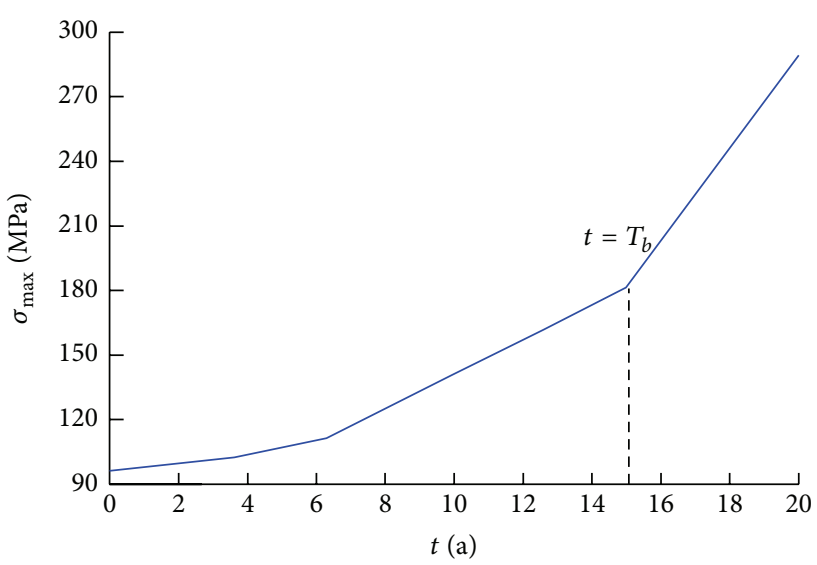

FIGURE 7: Curve of development of maximum stress of pile foundation under the condition of extreme load. 
pile foundation structure, the maximum stress should meet the following formula:

$$
\sigma_{\max } \leq[\sigma]=k \cdot \sigma_{s},
$$

where $[\sigma]$ is the allowable stress of the structure, $\mathrm{Mpa} ; \sigma_{s}$ is the yield stress of the material, and the yield stress of low alloy steel is $345 \mathrm{Mpa}$; $k$ is the safety coefficient of the structure, $k=0.725$ for the single pile foundation for the offshore wind turbine. Then, the allowable stress of the pile foundation structure is $[\sigma]=250 \mathrm{Mpa}$.

Under the normal operation condition, when $t=20 \mathrm{a}$, the corrosion rate of the steel pipe pile reaches the maximum and the internal stress can reach a peak value, and the peak value is

$$
\sigma_{\max }=82.6 \mathrm{Mpa}<[\sigma] .
$$

According to the calculation results, under the normal load conditions, the strength of the steel pipe pile for the wind turbine meets the safety requirements after homogeneous corrosion.

(2) Analysis of the Pile Foundation Stability. In addition to the strength requirements, the pile foundation structure should also meet the stability requirements. The structural stability can be calculated as per the formulas:

$$
\begin{aligned}
\sigma_{\max } & \leq\left[\sigma_{c}\right]=\varphi \cdot \sigma_{s}, \\
\varphi & =\frac{1-0.25 \lambda_{0}^{2}}{1.67+0.265 \lambda_{0}-0.044 \lambda_{0}^{3}}, \\
\lambda_{0} & =\frac{\lambda}{\lambda_{s}}, \\
\lambda & =\frac{K L}{r}, \\
\lambda_{s} & =\pi \sqrt{\frac{E}{\sigma_{S}}},
\end{aligned}
$$

where $\left[\sigma_{c}\right]$ is the structural buckling critical stress, Mpa. $\varphi$ is the stability coefficient. $\lambda_{0}$ is the relative slenderness ratio. $K$ is the length calculation coefficient, $K=1$ for the steel pipe pile. $L$ is the pile foundation length. $r$ is the calculation radius, and $r=0.35 \mathrm{D}$; $\mathrm{D}$ is the diameter of the pile.

Based on computation, the structure stability coefficient is $\varphi=0.502$, and the structural buckling critical stress is $\left[\sigma_{c}\right]=173.2 \mathrm{Mpa}$. Similarly, $\sigma_{\max }=82.6 \mathrm{Mpa}<\left[\sigma_{c}\right]$, so under the normal operation condition, the steel pipe pile for the wind turbine meets the structural stability requirements after homogeneous corrosion.

(3) Analysis of Reduction in Strength and Stability of the Steel Pipe Pile for the Wind Turbine Resulting from Homogeneous Corrosion. Based on the analysis of the strength and stability of the steel pipe pile for the wind turbine following corrosion action, it is known that the corrosion effect will lead to reduction in strength and stability of the offshore wind

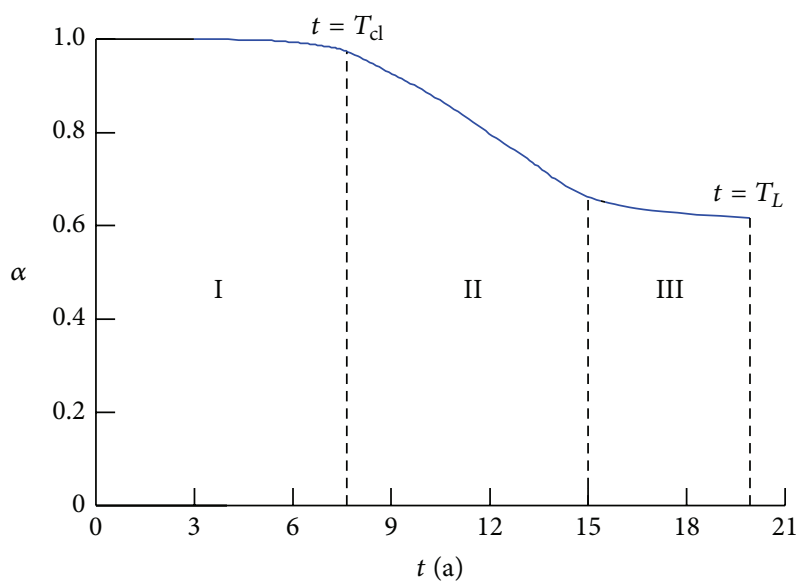

FIGURE 8: Effect of corrosion on reduction in pile foundation strength.

turbine foundation, but the reduced strength and stability are not beyond the scope of safe use. The parameter $\alpha$ is defined as the reduction coefficient of the strength for the pile foundation structure; if $\alpha=1$, it indicates that there is no corrosion strength damage occurring for the pile foundation structure; if $\alpha=0$, it indicates that the corrosion damage occurs for the pile foundation structure and the maximum stress of the pile foundation exceeds the scope of safe use. The parameter $\beta$ is defined as the reduction coefficient of corrosion for the stability of the overall structure of the pile foundation; if $\beta=1$, it indicates that there is no reduction occurring for the stability of the pile foundation structure with the corrosion damage; if $\beta=0$, it indicates that the stability of the pile foundation structure exceeds the scope of safe use due to the corrosion action.

It is known from the calculation result that the maximum deflection of the steel pipe pile for the wind turbine increases from $7.02 \mathrm{~cm}$ to $11.0 \mathrm{~cm}$ and increases by $2.98 \mathrm{~cm}$, and the maximum stress increases from $50.6 \mathrm{MPa}$ to $82.6 \mathrm{MPa}$; it increases by $32 \mathrm{Mpa}$ within a recovery phase of the corrosion protection system. Over the course of time, the reduction in the strength and stability of the steel pipe pile for the wind turbine arising from corrosion is nonlinear development. The strength reduction coefficient is $\alpha=0.63$ and the stability reduction coefficient is $\beta=0.52$ when $t=$ $20 \mathrm{a}$. The curve for the relationship between the strength reduction coefficient and the service time of the steel pipe pile structure is shown in Figure 8, and the curve for the relationship between the stability reduction coefficient and the service time of the steel pipe pile structure is shown in Figure 9.

Thus, we can obtain the strength and stability reduction regularity of the offshore steel pipe pile with the effect of the homogeneous corrosion under the normal operation conditions.

Stage I. Corrosion has the least effect on the strength and stability of the steel pipe pile for the wind turbine before the failure of the corrosion protection system. 


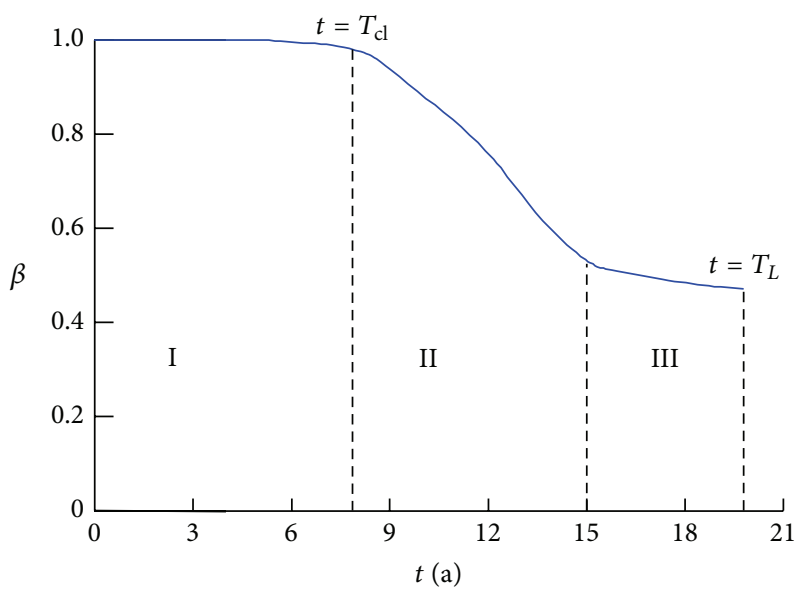

FIGURE 9: Effect of corrosion on reduction in pile foundation stability.

Stage II. The strength and stability of the steel pipe pile exhibit a negative exponential decrease after failure of the corrosion protection system.

Stage III. The corrosion rate of the steel pipe pile enters a stable stage. The reduction in strength and stability of the steel pipe pile for the wind turbine changes gently.

Its development regularity basically complies with the mathematical model of corrosion of steel pipe pile for the wind turbine. Thus, it can be used to verify the correctness of the mathematical model of corrosion of steel pipe pile for the wind turbine.

4.2. Extreme Load Conditions. Under the extreme load conditions, the allowable stress of the structure can increase by $20 \%$ in accordance with the specification. Then, the allowable stress is $[\sigma]=300 \mathrm{Mpa}$ under extreme load conditions. When $t=15 \mathrm{a}\left(T_{b}\right)$, it is known from the calculation result that $\sigma_{\max }=207 \mathrm{Mpa} \approx\left[\sigma_{c}\right] \leq[\sigma]$.

Based on the calculation of the corrosion rate for the offshore steel pipe pile, when $t=15 \mathrm{a}$, the corrosion rate of the steel pipe pile is $\Gamma=12 \%$, and the maximum stress of the steel pipe pile approaches the structural buckling critical stress $\left[\sigma_{c}\right]$ as a result of corrosion action. With the increasing of the corrosion time, the initial equilibrium conditions of the steel pipe pile structure will be broken, and the stability of the steel pipe pile for the wind turbine cannot be guaranteed under the extreme load conditions. When $t=20 \mathrm{a}$, the corrosion rate of the steel pipe pile is $\Gamma=15.8 \%$, and the peak value of the internal stress of the steel pipe pile for the wind turbine has exceeded the critical buckling stress. The strength reduction coefficient of the steel pipe pile is $\alpha=0.028$ and the stability reduction coefficient is $\beta=0$. At the moment, the steel pipe pile for the wind turbine has no bearing capacity. Therefore, the internal stress and deflection of the structure are developing rapidly.

The strength and stability reduction regularities of the offshore steel pipe pile with the effect of homogeneous corrosion are shown in Figures 10 and 11.

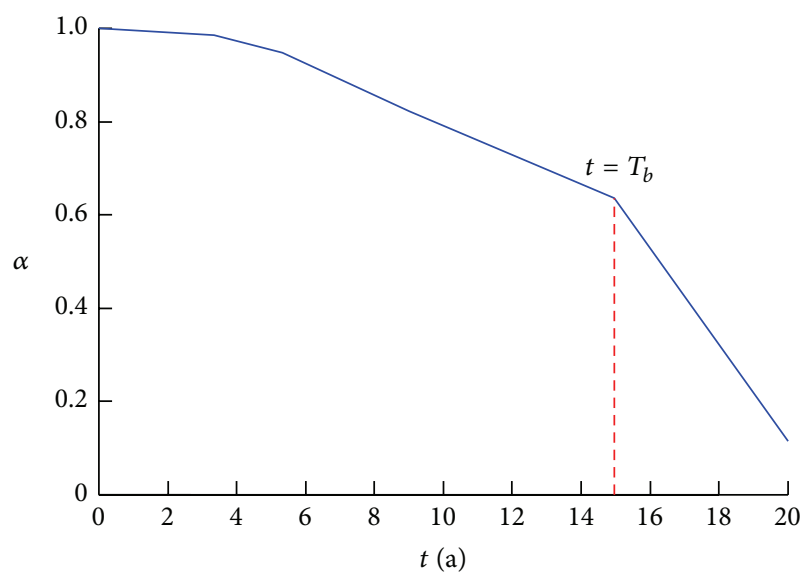

Figure 10: Effect of corrosion on reduction in pile foundation strength.

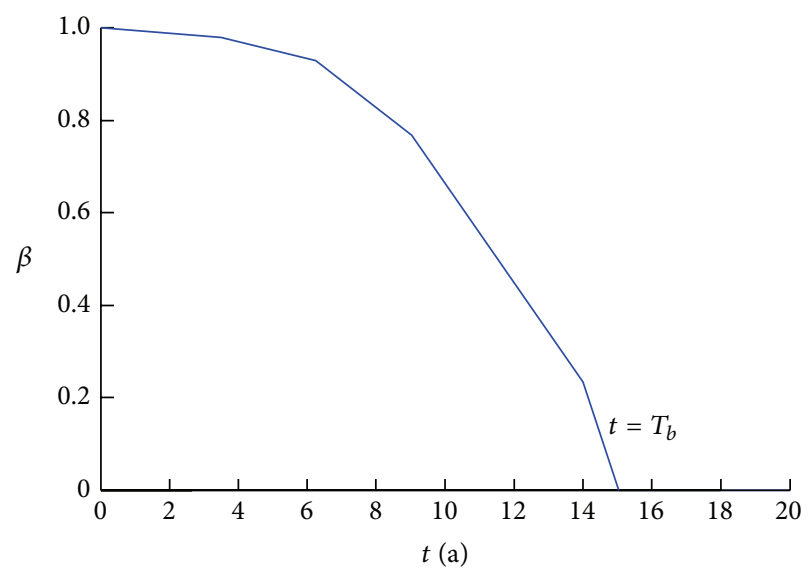

FIGURE 11: Effect of corrosion on reduction in pile foundation stability.

It is thus clear that the effect of corrosion is enormous for the strength and stability of the steel pipe pile under the extreme load conditions. Therefore, this stage must be avoided in design of the corrosion protection for the offshore steel pipe pile foundation of the wind turbine. Otherwise, there may be serious engineering accidents occurring and leading to huge economic loss.

\section{Conclusions}

(1) The mathematical models of corrosion for the offshore steel pipe pile foundation are determined based on the analysis of the corrosion models for the steel structure in the existing marine environments both at home and abroad, and the strength and stability reduction regularity of the wind turbine structure are researched under the effect of homogeneous corrosion.

(2) Under the normal operation condition, before the failure of the corrosion protection system, there are no effects on the strength and stability of the pile foundation structure under the homogeneous corrosion action. But after the failure 
of the corrosion protection system, with the corrosion action increasing rapidly, the strength and stability of the steel pipe pile exhibit a negative exponential decrease. In the end, after the corrosion rate enters a steady state, the strength and stability of the steel pipe pile enter a smooth development stage. In the whole stage, the maximum strength reduction coefficient of the steel pipe pile is 0.63 and the maximum stability reduction coefficient is 0.52 .

(3) Under the normal extreme load condition, at the initial stage of corrosion, the strength and stability reduction increases regularly depending on the corrosion rate. When the homogeneous corrosion rate of the steel pipe pile for the wind turbine is $\Gamma=12 \%$, the structure of the steel pipe pile for the wind turbine will reach the stability limit. And then the strength and stability of the steel pipe pile decrease sharply and the steel pipe pile for the wind turbine will lose stability under the influence of corrosion if corrosion continues to develop. When the homogeneous corrosion rate of the steel pipe pile is $\Gamma=15.8 \%$, the steel pipe pile for the wind turbine will reach its ultimate strength under the influence of corrosion and the steel pipe pile foundation for the wind turbine has no bearing capacity.

\section{Competing Interests}

There are no competing interests related to this paper.

\section{Acknowledgments}

The authors gratefully acknowledge the financial supports from the Natural Science Foundation Project of Chongqing under Grant no. cstc2013jjB0003 and the Specialized Research for the Doctoral Program of the Ministry of Education under Grant no. 20125522110004.

\section{References}

[1] R. Jeffrey and R. E. Melchers, "Corrosion of vertical mild steel strips in seawater," Corrosion Science, vol. 51, no. 10, pp. 22912297, 2009.

[2] J. H. Kim, E. Akiyama, H. Habazaki, A. Kawashima, K. Asami, and K. Hashimoto, "An XPS study of the corrosion behavior of sputter-deposited amorphous $\mathrm{Cr}-\mathrm{Nb}$ and $\mathrm{Cr}-\mathrm{Ta}$ alloys in $12 \mathrm{M}$ $\mathrm{HCl}$ solution," Corrosion Science, vol. 36, no. 3, pp. 511-523, 1994.

[3] X. Wang, J. Duan, J. zhang, and B. Hou, "Alloy elements' effect on anti-corrosion performance of low alloy steels in different sea zones," Materials Letters, vol. 62, no. 8-9, pp. 1291-1293, 2008.

[4] J. Ma and J. Wen, "Corrosion analysis of Al-Zn-In-Mg-Ti-Mn sacrificial anode alloy," Journal of Alloys and Compounds, vol. 496, no. 1-2, pp. 110-115, 2010.

[5] TSCF, "Experimental and theoretical investigation of the strength of corroded hull elements," Project 300, Tanker Structure Co-operative Forum, 1984.

[6] R. E. Melchers, "Pitting corrosion of mild steel in marine immersion environment-part 1: maximum pit depth," Corrosion, vol. 60, no. 9, pp. 824-836, 2004.

[7] R. E. Melchers, "The effect of corrosion on the structural reliability of steel offshore structures," Corrosion Science, vol. 47, no. 10, pp. 2391-2410, 2005.
[8] S. M. A. Shibli, B. Jabeera, and R. Manu, "Development of high performance aluminium alloy sacrificial anodes reinforced with metal oxides," Materials Letters, vol. 61, no. 14-15, pp. 30003004, 2007.

[9] B. Hou, Theory and Application of Marine Corrosion Environment, Science Press, Beijing, China, 1992.

[10] D. Jiang, X. Ma, and Y. Ding, "Coating of wind power dynamotor," Modern Paint \& Finishing, vol. 4, pp. 18-20, 2002.

[11] G. Zhang and Y. Li, "A contrast between compound sacrificial anode system and aluminum based anode system," Shipbuilding of China, vol. 11, no. 48, pp. 36-42, 2007.

[12] X. Liu, Y. Huang, B. Hou et al., "Galvanizing treatment of aluminum sacrificial anode surface and its electrochemical performance," Corrosion \& Protection, vol. 33, no. 1, pp. 1-4, 2012.

[13] S.-P. Qin, W.-C. Cui, and K. Shen, "A non-linear corrosion model for time variant reliability analysis of ship structures," Journal of Ship Mechanics, vol. 7, no. 1, pp. 94-102, 2003. 

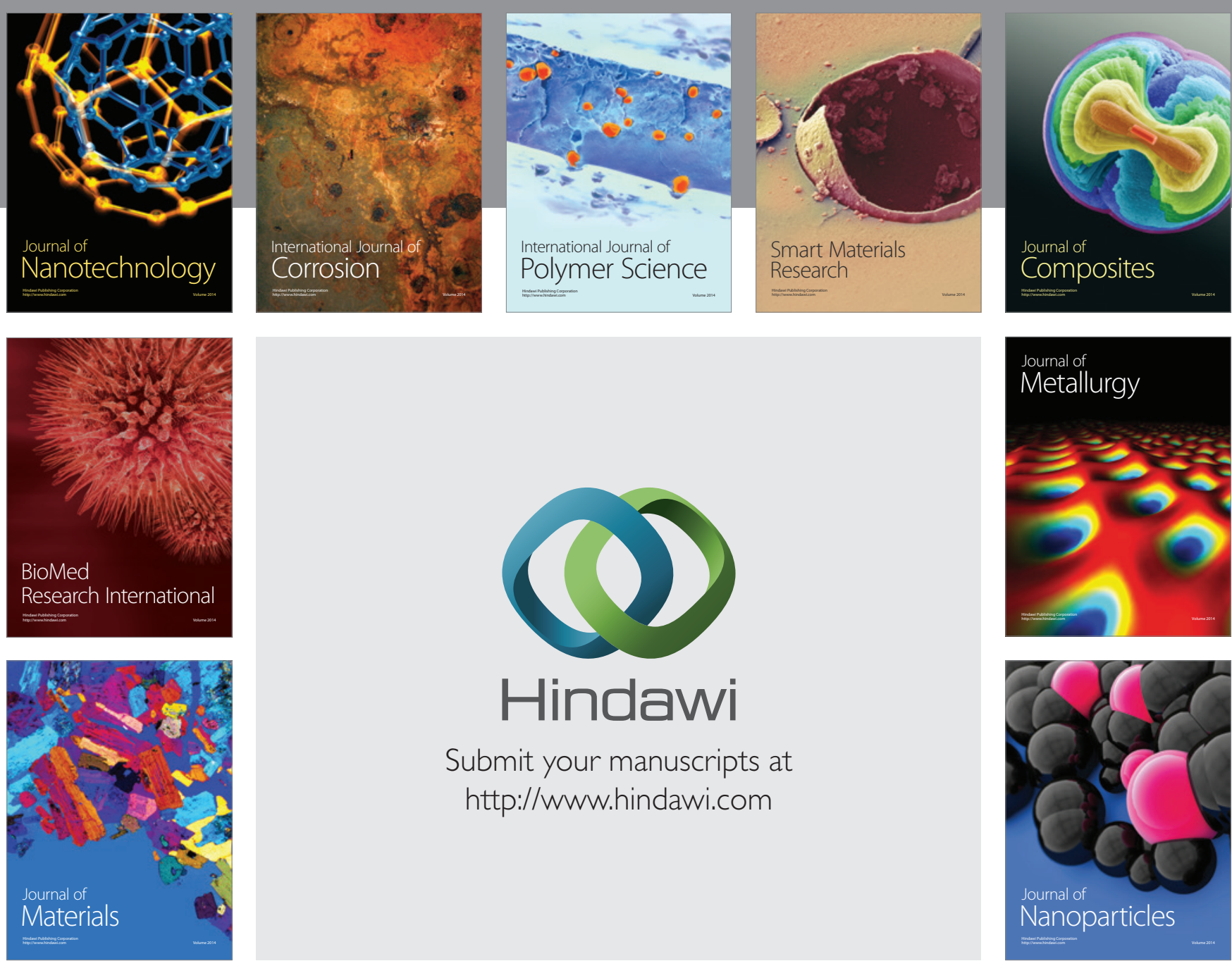

\section{Hindawi}

Submit your manuscripts at

http://www.hindawi.com

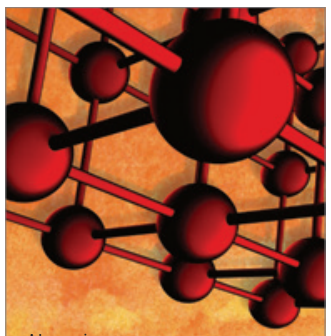

Materials Science and Engineering
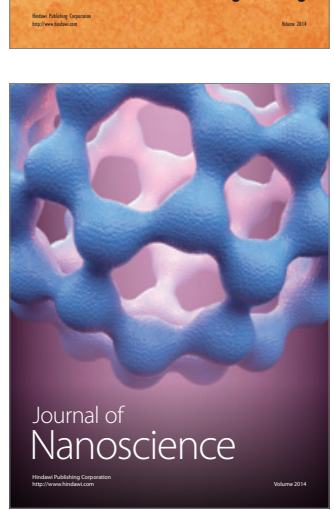
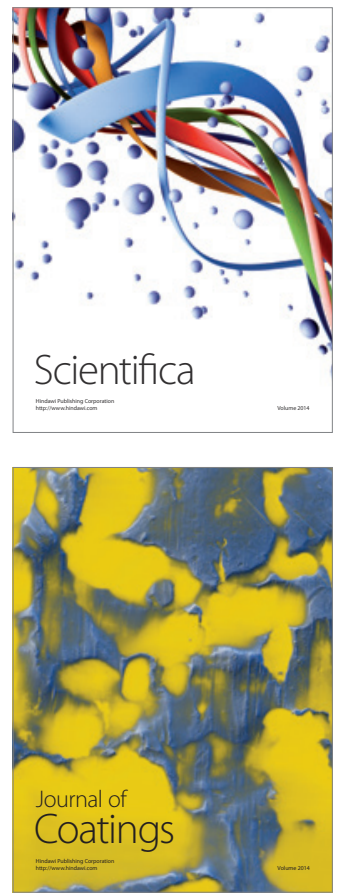
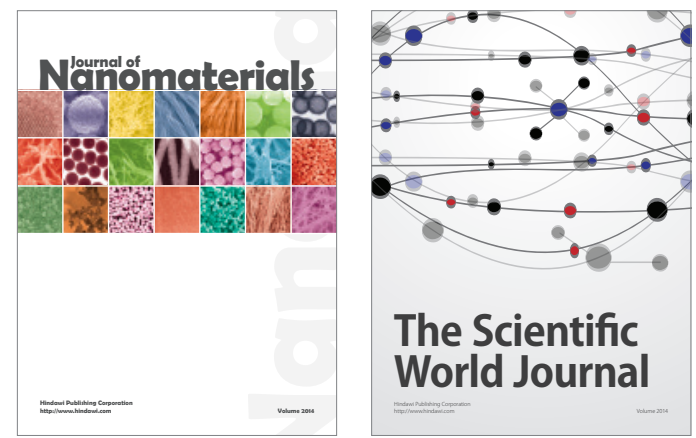

The Scientific World Journal
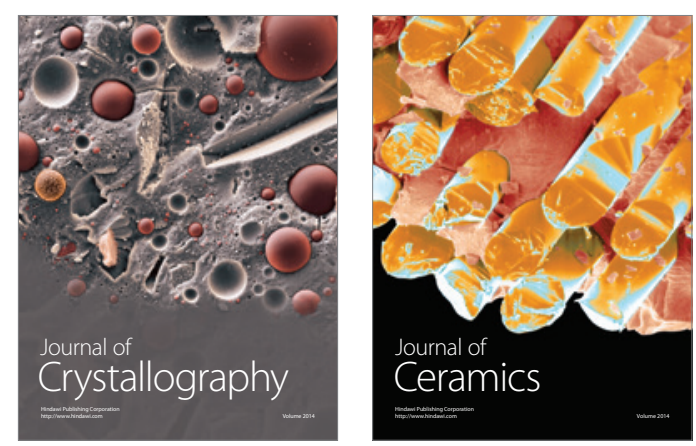
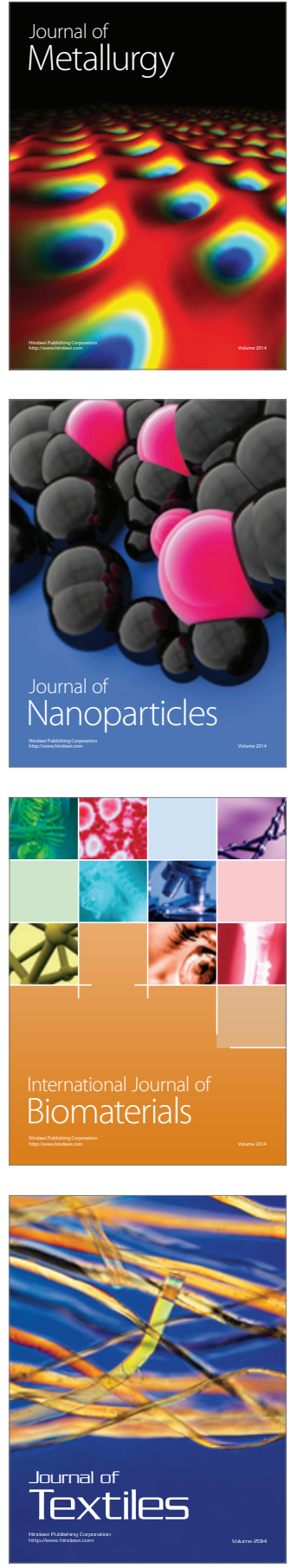